\title{
Comparison of Drug-Eluting Stents and Coronary Artery Bypass Grafting for the Treatment of Multivessel Coronary Artery Disease in Patients With Chronic Kidney Disease
}

\author{
Zhi Jian Wang, MD, PhD; Yu Jie Zhou, MD, PhD; Yu Yang Liu, MD; Dong Mei Shi, MD; \\ Ying Xin Zhao, MD; Yong He Guo, MD; Wan Jun Cheng, MD; Miao Yu, MD
}

\begin{abstract}
Background: Chronic kidney disease (CKD) is a strong predictor of mortality after percutaneous coronary intervention (PCI) or coronary artery bypass grafting $(\mathrm{CABG})$, but the relative efficacy of the 2 revascularization strategies in this context remains unknown.

Methods and Results: The 1,069 patients with CKD undergoing revascularization for multivessel coronary disease were evaluated. Of them, 532 patients were treated for 2-vessel disease (97 CABG, 435 PCI) and 537 for 3 -vessel disease (248 CABG, $289 \mathrm{PCI}$ ). CKD was defined as estimated glomerular filtration rate $<60 \mathrm{ml} / \mathrm{min}$. No differences between the PCI and CABG groups in the 2-vessel population were observed in the composite of death, myocardial infarction (MI) or cerebrovascular events $(10.6 \%$ vs $8.2 \%, \mathrm{P}=0.493)$ and repeat revascularization $(6.7 \%$ vs $3.1 \%, \mathrm{P}=0.181)$ during the 2 -year follow-up. In the 3-vessel population, patients undergoing PCI showed similar rate for the composite endpoint $(6.7 \%$ vs $3.1 \%, \mathrm{P}=0.181)$, but had a higher incidence of repeat revascularization $(12.5 \%$ vs $4.4 \%, \mathrm{P}=0.001)$ compared with the $\mathrm{CABG}$ group. After multivariate adjustment, revascularization strategy was not an independent predictor of the composite endpoint.

Conclusions: Compared with PCI with a drug-eluting stent, CABG showed a similar incidence of death, MI or cerebrovascular events in patients with multivessel disease and CKD, but was associated with decreased repeat revascularization in the 3-vessel population. (Circ J 2009; 73: 1228-1234)
\end{abstract}

Key Words: Coronary artery bypass grafting; Coronary heart disease; Drug-eluting stent (DES); Kidney; Survival

$\mathbf{P}$ ercutaneous coronary intervention (PCI) and coronary artery bypass grafting (CABG) are optional treatments for patients with multivessel coronary artery disease (CAD). Multiple studies comparing CABG with PCI for the treatment of multivessel CAD demonstrate similar mortality rates, but increased incidences of repeat revascularization after PCI!-12 In contrast, several large clinical registries reported that, compared with coronary stenting, CABG was associated with long-term survival benefits ${ }^{3-15}$ Importantly, in some meta-analyses and registries, CABG demonstrated greater benefit in mortality and myocardial infarction (MI) in high-risk patient subsets, such as those with diabetes or left ventricular (LV) dysfunction! $14-17$

Chronic kidney disease (CKD) is common in patients with coronary heart disease, estimated to affect approximately $25 \%$ of patients requiring coronary revascularization! ${ }^{18-25}$ It has been reported that the presence of CKD is associated with a higher risk of mortality among patients with CAD ${ }^{26-28}$ Multiple studies have also shown that CKD

(Received November 28, 2008; revised manuscript received February 4, 2009; accepted February 11, 2009; released online May 15, 2009) Department of Cardiology, Anzhen Hospital, Capital Medical University, Beijing, China

Mailing address: Yu Jie Zhou, MD, PhD, FACC, Department of Cardiology, Anzhen Hospital, Capital Medical University, Anzhenli district, Beijing 100029, China. E-mail: yjzhou@ @otmail.com

All rights are reserved to the Japanese Circulation Society. For permissions, please e-mail: cj@j-circ.or.jp is a potent independent predictor of death and subsequent cardiac events in patients undergoing revascularization. ${ }^{18-22}$ However, the data on whether CABG or PCI offers a better clinical outcome among CKD patients requiring coronary revascularization are very limited. Although several observational studies have compared the outcomes of participants with CKD and multivessel CAD who were assigned to CABG or PCI, those patients were not examined in the setting of the current practice of coronary implantation with a drug-eluting stent (DES) versus CABG 23,24 Therefore, in the present registry study, we compared the long-term outcomes of PCI with DES versus CABG in patients with multivessel CAD and CKD at a single high-volume center.

\section{Methods}

\section{Study Population}

Using the comprehensive revascularization database from Beijing Anzhen Hospital, whereby charts from patients undergoing a coronary intervention were reviewed by dedicated, independent investigators unaware of the objectives or purpose of the study, we evaluated 1,069 consecutive patients with multivessel CAD and CKD who underwent DES implantation or CABG between January 2004 and June 2006. We defined 2- and 3-vessel disease as the presence of 2 or 3 major epicardial coronary arteries with $\geq 70 \%$ diameter stenosis, determined visually by the cardiologist performing the first angiographic procedure. The method of revascularization was at the physician's and/or patient's 
discretion. The study design was reviewed and approved by the institutional research Ethics Committee, and all patients provided informed consent and the board guidelines. We excluded patients with unprotected left main CAD, acute MI with ST-segment elevation, cardiogenic shock, congenital or valvular heart disease, and those who had prior coronary stent implantation or prior CABG.

Preoperative serum creatinine levels were obtained from all patients, and renal function was assessed by estimated glomerular filtration rate (eGFR) calculated using the modified Modification of Diet in Renal Disease (MDRD) equation, which was modified from the original MDRD equation by adding a racial factor based on the Chinese population, and showed significant performance improvement in bias, precision, and accuracy compared with the original MDRD equations in Chinese patients 29 eGFR (ml. $\left.\min ^{-1} \cdot 1.73 \mathrm{~m}^{-2}\right)=186 \times(\text { serum creatinine level }[\mathrm{mg} / \mathrm{dl}])^{-1.154} \times$ (age [years] $)^{-0.203} \times 0.742$ (if female) $\times 1.227$. Participants with eGFR $<60 \mathrm{ml} / \mathrm{min}$ were defined as having CKD in this study, consistent with CKD stage 3-5 of the National Kidney Foundation classification ${ }^{30}$

\section{Revascularization Procedure}

PCI All patients underwent PCI according to current clinical guidelines, 31,32 with the interventional strategy at the discretion of the operator. All patients received a DES, comprising sirolimus-eluting stents, paclitaxel-eluting stents or zotarolimus-eluting stents. Weight-adjusted intra-procedural unfractionated heparin (with a goal-activated clotting time 250-300s) was administered during the procedure and was routinely discontinued at the end of the procedure. A loading dose of $600 \mathrm{mg}$ clopidogrel was given to all patients prior to PCI, followed by a maintenance dose of $75 \mathrm{mg}$ daily for 9-12 months unless severe bleeding complications occurred. In addition, all patients received $300 \mathrm{mg}$ aspirin daily, begun on the day of the procedure.

CABG Surgical revascularization was performed using standard bypass techniques. Mammary artery conduits were preferentially used for revascularization of the left anterior descending artery (LAD) whenever possible. Complete revascularization was performed when possible with arterial conduits or saphenous vein grafts. For those patients taking aspirin or clopidogrel, surgery was delayed at least 5 days. After the procedure, patients were administered $100 \mathrm{mg}$ aspirin per day indefinitely.

\section{Clinical Outcomes and Definitions}

The primary endpoint was a composite of all-cause death, non-fatal MI or cerebrovascular events (CVE). The second endpoint was repeat revascularization. MI was defined as any typical rise and fall of cardiac biomarkers in the setting of clinical signs or symptoms consistent with cardiac ischemia, following the American College of Cardiology definition ${ }^{33}$ Repeat revascularization included target vessel and nontarget vessel revascularization, regardless of whether the procedure was angiographically or clinically driven. CVE were divided into 3 categories: stroke, transient ischemic attack, and reversible ischemic neurological deficit, as determined by a neurologist.

Patients were contacted by telephone and interviewed about adverse events. Follow-up interviews and medical event classification were performed by independent investigators who were unaware of the objectives or purpose of the study. For those patients having reached at least 1 of the endpoints, a medical chart review was initiated to determine whether the event met the definitions described.

\section{Statistical Analysis}

Continuous variables are presented as mean $\pm S D$, and were compared using Student's t-test. Categorical variables are presented as frequencies and percentages. Because of the nonrandomized nature of this study, separate analysis was undertaken for the 2- and 3-vessel disease populations. Differences in baseline characteristics between groups were compared with chi-square tests, or exact tests if expected cell frequencies were small. Event-free survival estimates were created using Kaplan-Meier methods and compared with the log-rank test with respect to revascularization strategy. Predictors of long-term clinical outcomes were identified using Cox proportional hazards regression and multivariate analysis. The candidate variables were: revascularization strategy, age, gender, smoking status, history of prior MI, diagnosis of diabetes mellitus, hypertension, hypercholesterolemia, and LV dysfunction with ejection fraction $<30 \%$, acute coronary syndrome, proximal LAD disease and chronic total occlusion lesion.

All statistical analyses were 2-tailed, and a value of $\mathrm{P}<$ 0.05 was considered statistically significant. Analysis was performed with SPSS software, version 13.0 for windows (SPSS, Inc, Chicago, IL, USA).

\section{Results}

\section{Patient Sample Characteristics}

Of 6,487 patients undergoing either revascularization with DES (4,824 patients) or CABG (1,663 patients) for multivessel CAD during the study period, 1,069 patients (16.5\%) had CKD and were available for follow-up analysis. Among them, 724 underwent PCI with DES and 345 underwent CABG. In the DES group, a total of 2,353 DES were implanted, with the mean number of stents used per patient being 3.3 \pm 1.3 . Of these, 1,984 (84\%) were sirolimuseluting stents (Cypher Select, Cordis, Bridgewater, NJ, USA; Firebird, Microport, Shanghai, China; Excel, JW Medical, Weihai, China; or Partner, Lepu Medical Technology, Beijing, China), 164 (7\%) were paclitaxel-eluting stents (Taxus, Boston Scientific, Natick, MA, USA), and 205 (9\%) were zotarolimus-eluting stents (Endeavor, Medtronic, Minneapolis, MN, USA). The mean total length of stents implanted per patient was $64.2 \pm 29.8 \mathrm{~mm}$, and the average reference-vessel diameter was $2.9 \pm 0.4 \mathrm{~mm}$. In the CABG group, 284 patients $(82 \%)$ underwent off-pump surgery. Of the 173 patients with a proximal LAD lesion, $168(97 \%)$ underwent revascularization of the LAD with a mammary artery conduit.

Baseline clinical and angiographic characteristics according to revascularization strategy are shown in Table 1. A total of 532 patients were treated for 2-vessel disease (97 CABG, 435 DES) and 537 for 3-vessel disease (248 CABG, 289 DES). In the 3-vessel cohort, patients undergoing PCI with DES were more likely to have acute coronary syndrome compared with those who underwent CABG. In both the 2- and 3-vessel populations, patients receiving CABG had a strikingly higher prevalence of proximal LAD disease and chronic total occlusion.

\section{Clinical Outcomes}

Complete follow-up data for major clinical events were obtained in $96 \%$ of the overall cohort: $39.0 \%(n=282)$ of patients implanted with DES and $13.9 \%(n=41)$ of patients 
Table 1. Baseline Clinical and Angiographic Characteristics of Patients

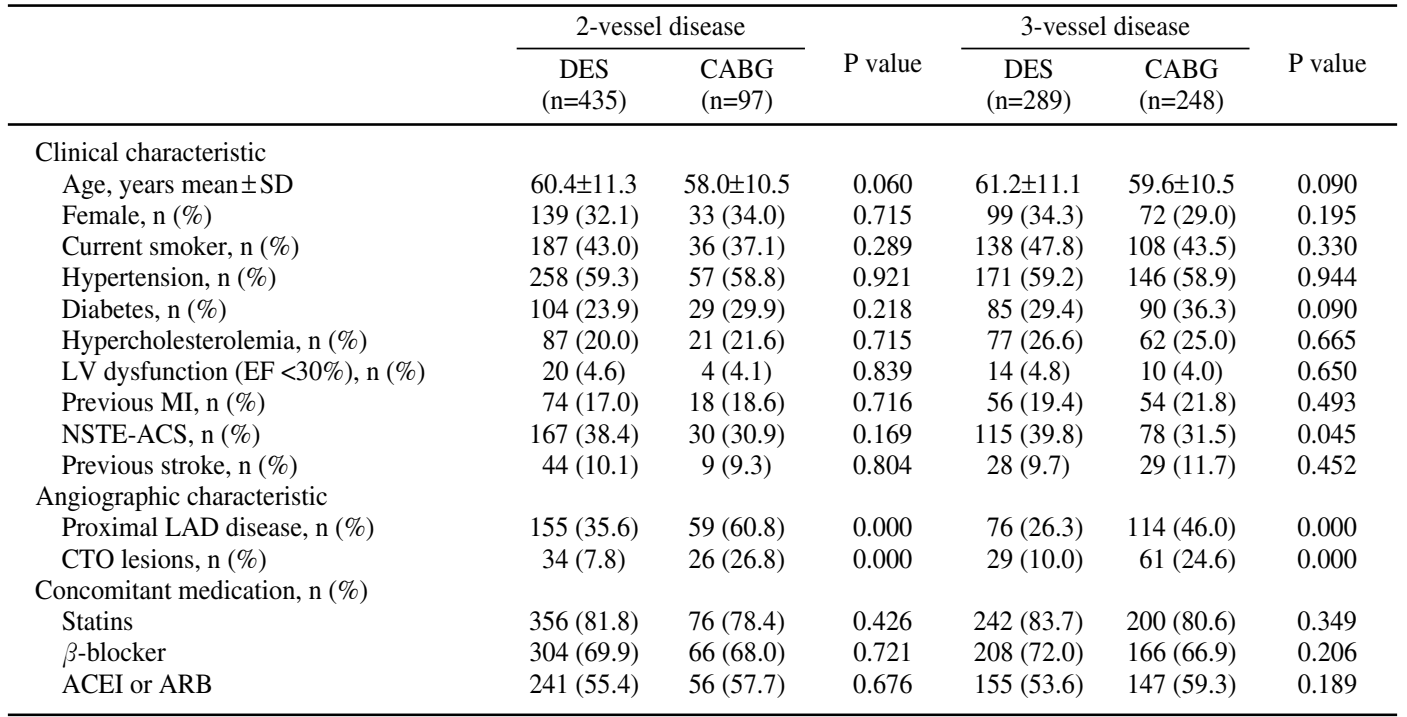

DES, drug-eluting stent; CABG, coronary artery bypass grafting; LV, left ventricular; EF, ejection fraction; MI, myocardial infarction; NSTE-ASC, non-ST segment elevation acute coronary syndrome; LAD, left anterior descending; CTO, chronic total occlusion; ACEI, angiotensin-converting enzyme inhibitor; ARB, angiotensin receptor blocker.
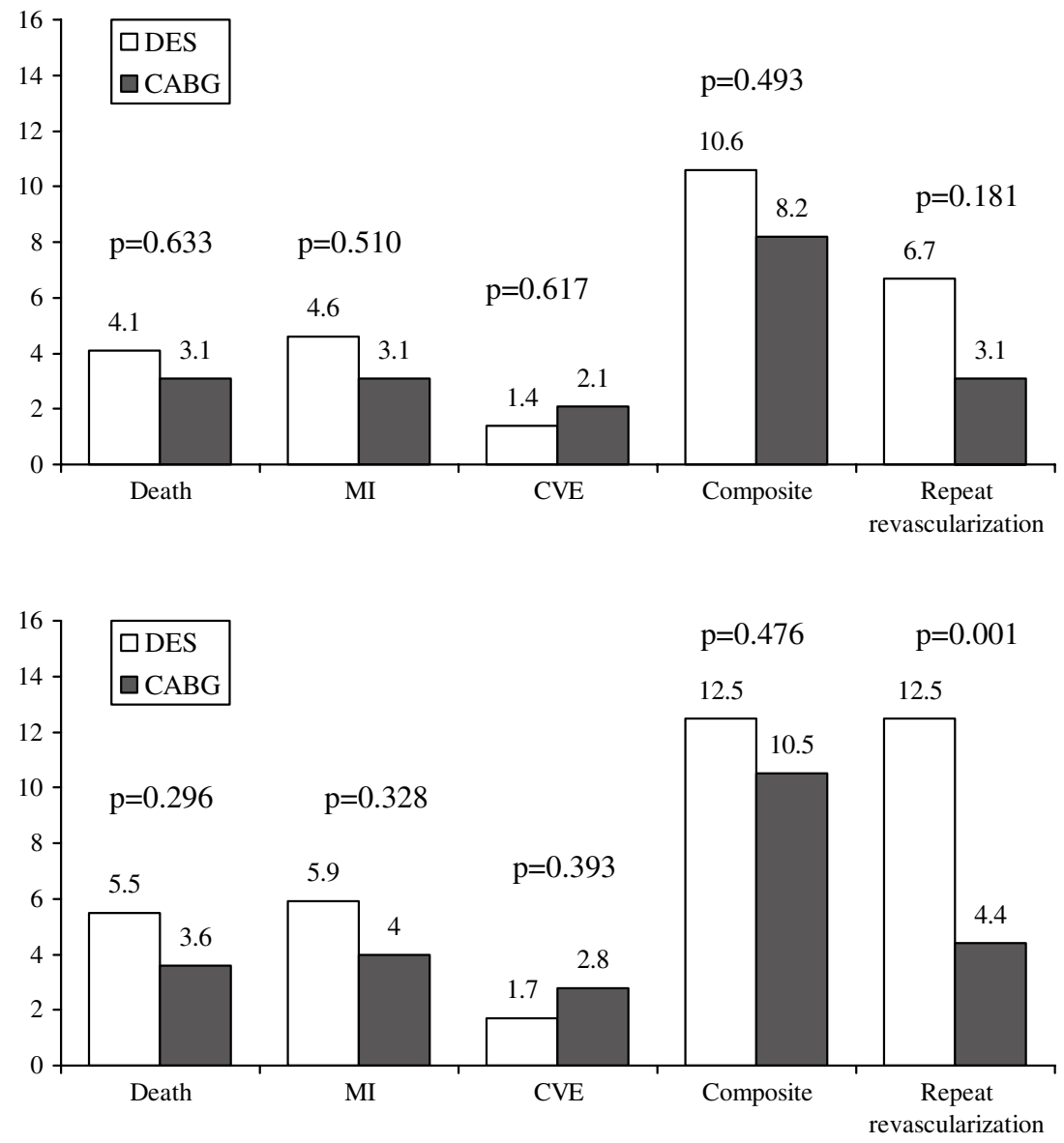

Figure 1. Two-year clinical outcomes after implantation with DES compared with CABG for patients with 2-vessel disease. CABG, coronary artery bypass grafting; CVE, cerebrovascular event; DES, drug-eluting stent; MI, myocardial infarction. undergoing CABG had follow-up angiography. The 2-year clinical outcomes for the overall 2- and 3-vessel coronary disease populations are shown in Figures 1 and 2. In the 2-vessel population, the incidence of the primary endpoint was very similar in patients receiving DES or CABG $(10.6 \%$ vs $8.2 \%, \mathrm{P}=0.493$ ), and there was no significant difference between the 2 treatment groups in the frequency of the individual outcomes of death, nonfatal MI or CVE. In the 2-vessel population, patients treated with DES also showed similar rates of repeat revascularization compared with 

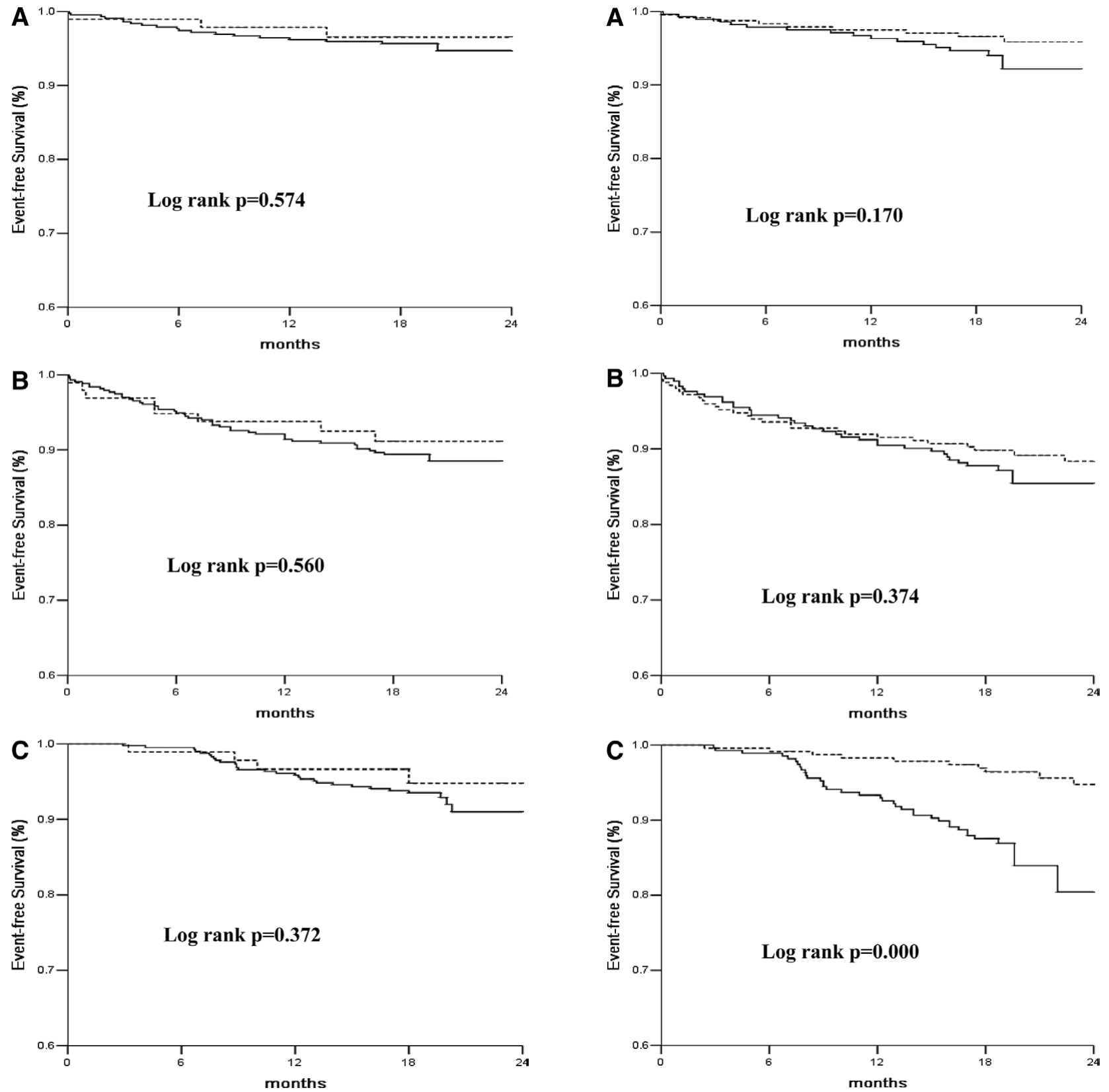

Figure 3. Two-year Kaplan-Meier survival curves for (A) all-cause death, (B) composite endpoint and (C) repeat revascularization in patients with 2-vessel disease undergoing drug-eluting stent implantation (solid line) or coronary artery bypass grafting (dotted line).

those undergoing $\mathrm{CABG}(6.7 \%$ vs $3.1 \%, \mathrm{P}=0.181)$.

In the 3-vessel population, there was also no significant difference between the DES and CABG groups in the frequency of the composite endpoint $(12.5 \%$ vs $10.5 \%, \mathrm{P}=$ 0.476 ) or in the individual outcomes of death, nonfatal MI or CVE. However, patients receiving a DES had a significantly higher rate of repeat revascularization as compared with patients who underwent $\mathrm{CABG}$ during the 2-year follow-up ( $12.5 \%$ vs $4.4 \%, \mathrm{P}=0.001)$.

Figures 3 and $\mathbf{4}$ depict the Kaplan-Meier event-free survival curves for the 2- and 3-vessel populations. There were no significant differences in cumulative death (Figures 3A, 4A) and the composite endpoint of death, MI and CVE (Figures 3B, 4B) between CABG and DES in either the 2- or

Figure 4. Two-year Kaplan-Meier survival curves for (A) all-cause death, (B) composite endpoint and (C) repeat revascularization in patients with 3-vessel disease undergoing drug-eluting stent implantation (solid line) or coronary artery bypass grafting (dotted line).

3 -vessel cohort during the 2 years of follow-up. In patients with 2-vessel disease, the 2 treatments showed similar survival rates free from repeat revascularization $(\log$-rank $\mathrm{P}=$ 0.372). In contrast, in the 3 -vessel cohort CABG was associated with a significantly higher survival rate free from repeat revascularization, as compared with PCI with DES, during the 2-year follow-up $(\log \operatorname{rank} \mathrm{P}=0.000)$.

\section{Multivariate Analyses}

As presented in Tables $\mathbf{2}$ and $\mathbf{3}$, multivariate Cox regression analysis of long-term outcome showed that the choice of revascularization strategy were not an independent predictor of the cumulative composite endpoint or death in either the 2- or 3-vessel populations during the 2 years of 
Table 2. Multivariate Predictors of Composite Endpoint, All-Cause Death and Repeat Revascularization for Patients With 2-Vessel Disease During 2-Year Follow-up

\begin{tabular}{lll}
\hline & Hazard ratio (95\%CI) & P value \\
\hline Composite endpoint & & \\
Revascularization strategy (DES/CABG) & $1.46(0.66-3.22)$ & 0.345 \\
Age (continuous) & $1.04(1.02-1.07)$ & 0.001 \\
Diabetes & $2.08(1.05-4.13)$ & 0.036 \\
LV dysfunction (EF <30\%) & $5.40(1.75-16.66)$ & 0.003 \\
$\quad$ Acute coronary syndrome & $2.26(1.15-4.44)$ & 0.018 \\
All-cause death & $1.76(0.48-6.46)$ & 0.397 \\
Revascularization strategy (DES/CABG) & $1.06(1.02-1.11)$ & 0.006 \\
Age (continuous) & $8.91(1.72-46.29)$ & 0.009 \\
LV dysfunction (EF <30\%) & $3.33(1.28-8.66)$ & 0.045 \\
Diabetes & $1.45(0.49-4.26)$ & 0.498 \\
Repeat revascularization & $2.17(1.33-3.62)$ & 0.003 \\
Revascularization strategy (DES/CABG) & $1.96(1.12-3.97)$ & 0.015 \\
Diabetes & & \\
Current smoker & & \\
\hline
\end{tabular}

CI, confidence interval. Other abbreviations see in Table 1.

Table 3. Multivariate Predictors of Composite Endpoint, All-Cause Death and Repeat Revascularization for Patients With 3-Vessel Disease During 2-Year Follow-up

\begin{tabular}{llc}
\hline & Hazard ratio (95\%CI) & P value \\
\hline Composite endpoint & & \\
Revascularization strategy (DES/CABG) & $1.32(0.77-2.23)$ & 0.311 \\
Age (continuous) & $1.03(1.01-1.06)$ & 0.019 \\
Diabetes & $1.96(1.16-3.30)$ & 0.012 \\
LV dysfunction (EF <30\%) & $5.61(1.72-18.35)$ & 0.004 \\
All-cause death & $1.79(0.73-4.43)$ & 0.206 \\
Revascularization strategy (DES/CABG) & $1.05(1.01-1.09)$ & 0.026 \\
Age (continuous) & $7.57(1.16-49.28)$ & 0.034 \\
LV dysfunction (EF <30\%) & $2.72(1.13-6.55)$ & 0.025 \\
Diabetes & $3.89(1.87-8.10)$ & 0.000 \\
Repeat revascularization & $2.04(1.09-3.82)$ & 0.027 \\
Revascularization strategy (DES/CABG) & $1.98(1.07-3.68)$ & 0.031 \\
Diabetes & & \\
Current smoker & & \\
\hline
\end{tabular}

Abbreviations see in Tables 1,2.

follow-up. In patients with 2-vessel disease, the choice of revascularization strategy was not an independent predictor of repeat revascularization (hazard ratio $1.45,95 \%$ confidence interval 0.49-4.26, $\mathrm{P}=0.498$ ). However, PCI with DES was independently associated with a higher risk of repeat revascularization in patients with 3-vessel disease compared with $\mathrm{CABG}$ (hazard ratio $3.89,95 \%$ confidence interval $1.87-8.10, \mathrm{P}=0.000$ ).

\section{Discussion}

In this large observational study of consecutive patients with 2- or 3-vessel CAD and CKD, we found that patients undergoing PCI with multivessel DES implantation had similar rates of death, MI or CVE as those who underwent CABG. However, subjects receiving DES as treatment for 3-vessel disease had substantially higher rates of subsequent revascularization compared with those undergoing $\mathrm{CABG}$ in the 2-year follow-up.

Several observational studies have compared CABG and PCI, first with BMS and then with DES, in patients with multivessel CAD ${ }^{12-15}$ The Arterial Revascularization Therapies Study (ARTS) II study, which compared outcomes of patients treated with sirolimus-eluting stents and that of the surgical arm of the ARTS trial, demonstrated that implanta- tion with DES was associated with similar 1-year outcomes as $\mathrm{CABG}^{34}$ In a large multicenter registry study from Korea, adjusted long-term mortality risk was equivalent in patients who underwent PCI with DES implantation or CABG, although the subsequent revascularization rate was considerably higher in the DES group ${ }^{12}$ In contrast, another large single-center registry study showed that CABG resulted in improved major adverse cardiovascular and CVE in patients with multivessel disease compared with PCI with DES, primarily in those with diabetes ${ }^{15}$ Also, in several studies and in a meta-analysis, CABG demonstrated benefit in death and MI in high-risk patient subgroups such as those with diabetes or with LV dysfunction! $14,16,17$

Moderate or severe CKD is highly prevalent and represents an important high-risk subset of patients undergoing revascularization $18-25$ CKD is significantly associated with increased mortality, MI, acute renal failure and restenosis after PCI $1{ }^{18-20}$ and also has an adverse prognosis after CABG, probably because of the longer postoperative mechanical ventilation time, higher postoperative bleeding rates, and increased length of hospital stay.1,22 Despite moderate or severe CKD having been confirmed as an independent predictor of mortality or morbidity after revascularization with PCI or $\mathrm{CABG}{ }^{18-22}$ limited data are available on the treatment effect of choice of revascularization strategy (PCI or 
$\mathrm{CABG}$ ) in this high-risk patient subset. In a large observational study based on 4,584 patients undergoing revascularization, CABG was found to be associated with significant survival benefit compared with PCI among patients with moderate and severe CKD not demonstrated among patients with normal renal function and mild CKD 23 In contrast, the post hoc analysis from the ARTS trial showed that, among patients with multivessel CAD and CKD, treatment with $\mathrm{CABG}$ or PCI with multivessel stenting led to similar outcomes of death, MI or stroke ${ }^{4}$ Those 2 studies, however, have limited applicability to current practice, primarily because they were both based on patients undergoing PCI with BMS or balloon angioplasty.

To our knowledge, this observational study is the first to compare the clinical outcomes of patients with multivessel CAD and CKD who underwent either CABG or PCI with DES. The availability of DES has been shown to significantly reduce clinical and angiographic restenosis in patients with preserved, as well as impaired, baseline renal function. ${ }^{35-38}$ Despite that finding, in our study the use of DES did not offer an incremental benefit in the rates of death, MI or CVE, and was still associated with a higher risk of repeat revascularization in the 3 -vessel population, as compared with CABG. However, the rate of follow-up angiography in the DES group was significantly higher than in the CABG group $(39.0 \%$ vs $13.9 \%, \mathrm{P}=0.000)$, so the rate of asymptomatic graft stenosis or occlusion may have been dramatically underestimated in the $\mathrm{CABG}$ group relative to the DES group.

The choice of revascularization strategy for the treatment of multivessel disease depends on several factors, including patient characteristics, LV function, severity of involved coronary disease, and the presence of comorbidities. There is increasing information that treatment with $\mathrm{CABG}$ offers greater survival benefit over PCI in specific high-risk patient subgroups $!^{14-17}$ In our study, however, we found that DES and CABG had equivalent rates of death, MI or CVE among patients with CKD and with either 2- or 3-vessel disease. Our results suggest that PCI with DES is an acceptable and less invasive alternative to $\mathrm{CABG}$ in this high-risk patient subset, but possibly at the expense of increased repeat revascularization within 2 years.

\section{Study Limitations}

First, this was a single-center nonrandomized, observational data, which may lead to several potential biases. For instance, in the 3-vessel population, the PCI group had a larger proportion of patients with acute coronary syndrome, whereas in both the 2- and 3-vessel populations, the CABG group had a strikingly higher prevalence of proximal LAD disease and chronic total occlusion lesions. Furthermore, the choice of revascularization was at the discretion of the treating physician or patient and that indication bias may affect the results of our study in that the indication for treatment may affect the outcome. Although this bias may not be entirely obviated, it was minimized by the adjustment of factors such as patient's characteristics, presence of comorbidities, severity of CAD and LV dysfunction by using multivariable Cox modeling. Despite this, future randomized prospective studies are urgently indicated. Second, the sample size of patients with CKD makes our analysis underpowered to detect significant differences in mortality between DES and CABG. Nonsignificant trends toward higher death and MI rates and lower CVE rate were seen in patient who received DES, especially in the 3-vessel popu- lation; these trends might have been significant with a larger cohort of patients. Thirdly, we relied on estimated GFR, which is an imprecise measure of renal function; however, the gold standard for measurement of GFR is labor-intensive and expensive 39 Fourthly, the definition of CKD is not specific and ranges from stage 3 to 5 of the National Kidney Foundation classification. Because of the sample size limitation, we did not further analyze differences in clinical outcome among different stages of CKD. Finally, follow-up angiography was not mandatory and because of the lower rate of follow-up angiography in CABG group compared with the DES group, it is prudent to draw the conclusion that $\mathrm{CABG}$ is superior over DES on the need for repeat procedure.

In conclusion, this observational study is the first to compare the clinical outcomes of patients with multivessel CAD and CKD who underwent either CABG or PCI with DES. Our results suggest that patients undergoing PCI with multivessel DES implantation have comparable long-term rates of death, MI or CVE as those who undergo CABG. Despite the use of DES, patients with 3-vessel disease receiving DES had substantially higher rates of subsequent revascularization compared with those undergoing $\mathrm{CABG}$ at the 2-year follow-up. Conclusions regarding the comparison of these 2 treatment strategies for this high-risk patient subset await results from future prospective randomized trials.

\section{References}

1. Coronary angioplasty versus coronary artery bypass surgery: The Randomized Intervention Treatment of Angina (RITA) trial. Lancet 1993; 341: $573-580$.

2. Rodriguez A, Boullon F, Perez-Baliño N, Paviotti C, Liprandi MI, Palacios IF. Argentine randomized trial of percutaneous transluminal coronary angioplasty versus coronary artery bypass surgery in multivessel disease (ERACI): In-hospital results and 1-year follow-up: ERACI Group. J Am Coll Cardiol 1993; 22: 1060-1067.

3. Hamm CW, Reimers J, Ischinger T, Rupprecht HJ, Berger J, Bleifeld W. A randomized study of coronary angioplasty compared with bypass surgery in patients with symptomatic multivessel coronary disease: German Angioplasty Bypass Surgery Investigation (GABI). N Engl J Med 1994; 331: 1037-1043.

4. King SB III, Lembo NJ, Weintraub WS, Kosinski AS, Barnhart HX, Kutner $\mathrm{MH}$, et al. A randomized trial comparing coronary angioplasty with coronary bypass surgery: Emory Angioplasty versus Surgery Trial (EAST). N Engl J Med 1994; 331: 1044-1050.

5. BARI Investigators. Comparison of coronary bypass surgery with angioplasty in patients with multivessel disease: The Bypass Angioplasty Revascularization Investigation. $N$ Engl J Med 1996; 335: 217-225.

6. Solomon AJ, Gersh BJ. Management of chronic stable angina: Medical therapy, percutaneous transluminal coronary angioplasty, and coronary artery bypass graft surgery: Lessons from the randomized trials. Ann Intern Med 1998; 128: 216-223.

7. Rodriguez A, Bernardi V, Navia J, Baldi J, Grinfeld L, Martinez J, et al. Argentine Randomized Study: Coronary angioplasty with stenting versus coronary bypass surgery in patients with multiple-vessel disease (ERACI II): 30-day and one-year follow-up results: ERACI II Investigators. J Am Coll Cardiol 2001; 37: 51-58.

8. Serruys PW, Unger F, Sousa JE, Jatene A, Bonnier HJ, Schonberger JP, et al, for the Arterial Revascularization Therapies Study Group. Comparison of coronary-artery bypass surgery and stenting for the treatment of multivessel disease. N Engl J Med 2001; 344: 11171124.

9. Morrison DA, Sethi G, Sacks J, Henderson W, Grover F, Sedlis S, et al; Angina With Extremely Serious Operative Mortality Evaluation (AWESOME). Percutaneous coronary intervention versus coronary artery bypass graft surgery for patients with medically refractory myocardial ischemia and risk factors for adverse outcomes with bypass: A multicenter, randomized trial: The Investigators of the Department of Veterans Affairs Cooperative Study \#385, the Angina With Extremely Serious Operative Mortality Evaluation (AWESOME). J Am 
Coll Cardiol 2001; 38: 143-149.

10. SoS Investigators. Coronary artery bypass surgery versus percutaneous coronary intervention with stent implantation in patients with multivessel coronary artery disease (the Stent or Surgery trial): A randomized controlled trial. Lancet 2002; 360: 965-970.

11. Mercado N, Wijns W, Serruys PW, Sigwart U, Flather MD, Stables $\mathrm{RH}$, et al. One-year outcomes of coronary artery bypass graft surgery versus percutaneous coronary intervention with multiple stenting for multisystem disease: A meta-analysis of individual patient data from randomized clinical trials. J Thorac Cardiovasc Surg 2005; 130: 512-519.

12. Park DW, Yun SC, Lee SW, Kim YH, Lee CW, Hong MK, et al. Long-term mortality after percutaneous coronary intervention with drug-eluting stent implantation versus coronary artery bypass surgery for the treatment of multivessel coronary artery disease. Circulation 2008; 117: 2079-2086.

13. Brener SJ, Lytle BW, Casserly IP, Schneider JP, Topol EJ, Lauer MS. Propensity analysis of long-term survival after surgical or percutaneous revascularization in patients with multivessel coronary artery disease and high-risk features. Circulation 2004; 109: 2290 2295.

14. Hannan EL, Racz MJ, Walford G, Jones RH, Ryan TJ, Bennett E, et al. Long-term outcomes of coronary-artery bypass grafting versus stent implantation. N Engl J Med 2005; 352: 2174-2183.

15. Javaid A, Steinberg DH, Buch AN, Corso PJ, Boyce SW, Pinto Slottow TL, et al. Outcomes of coronary artery bypass grafting versus percutaneous coronary intervention with drug-eluting stents for patients with multivessel coronary artery disease. Circulation 2007; 116: I-200-I-206.

16. Influence of diabetes on 5-year mortality and morbidity in a randomized trial comparing CABG and PTCA in patients with multivessel disease: The Bypass Angioplasty Revascularization Investigation (BARI). Circulation 1997; 96: $1761-1769$.

17. Hoffman SN, TenBrook JA, Wolf MP, Pauker SG, Salem DN, Wong JB. A meta-analysis of randomized controlled trials comparing coronary artery bypass graft with percutaneous transluminal coronary angioplasty: One- to eight-year outcomes. J Am Coll Cardiol 2003; 41: $1293-1304$

18. Blackman DJ, Pinto R, Ross JR, Seidelin PH, Ing D, Jackevicius C, et al. Impact of renal insufficiency on outcome after contemporary percutaneous coronary intervention. Am Heart J 2006; 151: 146-152.

19. Best PJ, Lennon R, Ting HH, Bell MR, Rihal CS, Holmes DR, et al. The impact of renal insufficiency on clinical outcomes in patients undergoing percutaneous coronary interventions. $J$ Am Coll Cardiol 2002; 39: 1113-1119.

20. Koganei H, Kasanuki H, Ogawa H, Tsurumi Y. Association of glomerular filtration rate with unsuccessful primary percutaneous coronary intervention and subsequent mortality in patients with acute myocardial infarction: From the HIJAMI registry. Circ J 2008; 72: $179-185$.

21. Cooper WA, O'Brien SM, Thourani VH, Guyton RA, Bridges CR, Szczech LA, et al. Impact of renal dysfunction on outcomes of coronary artery bypass surgery: Results from the Society of Thoracic Surgeons National Adult Cardiac Database. Circulation 2006; 113: $1063-1070$.

22. Hillis GS, Croal BL, Buchan KG, El-Shafei H, Gibson G, Jeffrey $\mathrm{RR}$, et al. Renal function and outcome from coronary artery bypass grafting: Impact on mortality after a 2.3-year follow-up. Circulation 2006; 113: $1056-1062$.

23. Reddan DN, Szczech LA, Tuttle RH, Shaw LK, Jones RH, Schwab SJ, et al. Chronic kidney disease, mortality, and treatment strategies among patients with clinically significant coronary artery disease. J Am Soc Nephrol 2003; 14: 2373-2380.

24. Ix JH, Mercado N, Shlipak MG, Lemos PA, Boersma E, Lindeboom $\mathrm{W}$, et al. Association of chronic kidney disease with clinical outcomes after coronary revascularization: The Arterial Revascularization Therapies Study (ARTS). Am Heart J 2005; 149: 512-519.

25. Zhang Q, Ma CS, Nie SP, Du X, Lv Q, Kang JP, et al. Prevalence and impact of renal insufficiency on clinical outcomes of patients under- going coronary revascularization. Circ J 2007; 71: 1299-1304.

26. Anavekar NS, McMurray JJ, Velazquez EJ, Solomon SD, Kober L, Rouleau JL, et al. Relation between renal dysfunction and cardiovascular outcomes after myocardial infarction. N Engl J Med 2004; 351: $1285-1295$

27. Shlipak MG, Heidenreich PA, Noguchi H, Chertow GM, Browner WS, McClellan MB. Association of renal insufficiency with treatment and outcomes after myocardial infarction in elderly patients. Ann Intern Med 2002; 137: 555-562.

28. Lee SH, Kim YJ, Kim W, Park JS, Shin DG, Hur SH, et al, Korean Acute Myocardial Infarction Registry Investigators. Clinical outcomes and therapeutic strategy in patients with acute myocardial infarction according to renal function: Data from the Korean Acute Myocardial Infarction Registry. Circ J 2008; 72: 1410-1418.

29. Ma YC, Zuo L, Chen JH, Luo Q, Yu XQ, Li Y, et al. Modified glomerular filtration rate estimating equation for Chinese patients with chronic kidney disease. J Am Soc Nephrol 2006; 17: 2937-2944.

30. K/DOQI Clinical practice guidelines for chronic kidney disease: Evaluation, classification, and stratification: Kidney Disease Outcome Quality Initiative. Am J Kidney Dis 2002; 39: S1 -S246.

31. Smith SC Jr, Feldman TE, Hirshfeld JW Jr, Jacobs AK, Kern MJ, King SB 3rd, et al, for the American College of Cardiology/American Heart Association Task Force on Practice Guidelines, ACC/AHA/ SCAI Writing Committee to Update 2001 Guidelines for Percutaneous Coronary Intervention. ACC/AHA/SCAI 2005 guideline update for percutaneous coronary intervention: A report of the American College of Cardiology/American Heart Association Task Force on Practice Guidelines (ACC/AHA/SCAI Writing Committee to Update 2001 Guidelines for Percutaneous Coronary Intervention). Circulation 2006; 113: e166-e286.

32. Eagle KA, Guyton RA, Davidoff R, Edwards FH, Ewy GA, Gardner TJ, et al, for the American College of Cardiology, American Heart Association. ACC/AHA 2004 guideline update for coronary artery bypass graft surgery: A report of the American College of Cardiology/ American Heart Association Task Force on Practice Guidelines (Committee to Update the 1999 Guidelines for Coronary Artery Bypass Graft Surgery). Circulation 2004; 110: e340-e437.

33. Cannon CP, Battler A, Brindis RG, Cox JL, Ellis SG, Every NR, et al. American College of Cardiology key data elements and definitions for measuring the clinical management and outcomes of patients with acute coronary syndromes: A report of the American College of Cardiology Task Force on Clinical Data Standards (Acute Coronary Syndromes Writing Committee). J Am Coll Cardiol 2001; 38: 2114 2130.

34. Serruys PW, Ong ATL, Morice MC, De Bruyne B, Colombo A, Macaya C, et al, for the ARTS II Investigators. Arterial Revascularization Therapies Study, part II: Sirolimus-eluting stents for the treatment of patients with multivessel de novo coronary lesions. Eurointervention 2005; 1: 147-156.

35. Ishio N, Kobayashi Y, Takebayashi H, Iijima Y, Kanda J, Nakayama $\mathrm{T}$, et al. Impact of drug-eluting stents on clinical and angiographic outcomes in dialysis patients. Circ J 2007; 71: 1525-1529.

36. Halkin A, Mehran R, Casey CW, Gordon P, Matthews R, Wilson $\mathrm{BH}$, et al. Impact of moderate renal insufficiency on restenosis and adverse clinical events after paclitaxel-eluting and bare metal stent implantation: Results from the TAXUS-IV Trial. Am Heart J 2005; 150: $1163-1170$.

37. Jeong YH, Hong MK, Lee CW, Park DW, Kim YH, Kim JJ, et al. Impact of significant chronic kidney disease on long-term clinical outcomes after drug-eluting stent versus bare metal stent implantation. Int J Cardiol 2008; 125: 36-40.

38. Okada T, Hayashi Y, Toyofuku M, Imazu M, Otsuka M, Sakuma T, et al. One-year clinical outcomes of dialysis patients after implantation with sirolimus-eluting coronary stents. Circ J 2008; 72: 1430-1435.

39. Coresh J, Toto RD, Kirk KA, Whelton PK, Massry S, Jones C, et al. Creatinine clearance as a measure of GFR in screenees for the African American study of kidney disease and hypertension pilot study. Am $J$ Kidney Dis 1998; 32: 32-42. 